\title{
Correlates of ever had sex among perinatally HIV-infected adolescents in Uganda
}

\author{
Scovia Nalugo Mbalinda ${ }^{*}$, Noah Kiwanuka ${ }^{2}$, Lars E. Eriksson ${ }^{3,4,5}$, Rhoda K. Wanyenze ${ }^{2}$ and Dan Kabonge Kaye ${ }^{6}$
}

\begin{abstract}
Background: The objective of this study was to explore the correlates of ever had sex among perinatally HIV-infected (PHIV) adolescents.

Methods: A cross-sectional survey of sexual behaviour was conducted with 624 PHIV adolescents living three regions (12 districts) of Uganda. Data was collected on socio demographic characteristics (age, sex, occupation, religion and education status), sexual practices and behaviours (Intimate relationships, sexual intercourse, age of sexual debut, condom use, multiple and concurrent sexual partners), consequences of sexual behaviours (pregnancy and STI's) and life style factors (use of alcohol, psychoactive substances and peer influence). Multivariable logistic-regression was used to ascertain the determinants of sexual activity.
\end{abstract}

Results: The majority of PHIV were female (59.3\%) and the mean age of the sample was $16.2( \pm 2.1)$ years. The mean age of sexual debut was 15.8 years; $16.2 \%$ (101/624) reported symptoms for sexually transmitted infections (STI) and more than a third (213/624) reported ever had sex.Of these $76.5 \%$ (165/213) used condoms inconsistently; and $49.3 \%$ (105/213) had been pregnant or made someone pregnant. Of those in relationships, $56.3 \%$ (223/396) did not disclose and were not aware of their partners' HIV status. Adolescents aged 15-19 years were more likely to have ever been sexually active (Adjusted odds ratio (AOR) 6.28, 95 \% Confidence interval (Cl): 2.63-14.99) compared to those aged 10-14 years. Adolescents who were living alone were more likely to have ever been sexually active compared to those living with one or both parents (AOR 4.33, $95 \% \mathrm{Cl}$ : 1.13-16.62). The odds of being sexually active were lower among adolescents in school compared to those out of school (AOR 0.2, $95 \% \mathrm{Cl}$ : 0.13-0.30), who had never been treated for STI (compared to those who had never been treated for STI) (AOR 0.19, $95 \%$ 0.11-0.32) and adolescents who never drank alcohol (AOR 0.49, $95 \% \mathrm{Cl}$ 0.28-0.87).

Conclusion: PHIV adolescents have risky sexual behaviours characterized by being sexually active, inconsistent condom use, and having partners of unknown status. Risk reduction interventions are required to minimize unplanned pregnancies, STI, and HIV transmission by PHIV adolescents.

Keywords: HIV, Perinatally infected, Adolescents, Risky sexual behaviour, Adolescents, Uganda

\section{Background}

The global paediatric HIV epidemic has shifted into a new phase as children on antiretroviral therapy (ART) grow into adolescence and adulthood, where they face new challenges of living with HIV [1]. Like other adolescents, perinatally HIV-infected adolescents (PHIV) experience challenges related to their stage of development as they enter puberty [2]. The PHIV mature physiologically and psychologically and become sexually

\footnotetext{
* Correspondence: snmbalinda@gmail.com

'Department of Nursing, Makerere University, Kampala, Uganda

Full list of author information is available at the end of the article
}

active. Initiation of sexual activity during adolescence among PHIV predisposes them to risk of pregnancy and STI'sincluding acquiring other strains of HIV and infecting other adolescents which compounds the HIV infection rates $[2,3]$.

Globally, it is estimated that about 2.1 million adolescents (10-19 years) are HIV positive [4]. Most of these adolescents acquired HIV perinatally from their HIV infected mothers during pregnancy, birth or when they were breastfed. Nearly 2 million of these adolescents live in sub-Saharan Africa: $70 \%$ of whom live in South Africa, Nigeria, Kenya, Tanzania, Uganda, 
Zimbabwe, Mozambique, Zambia, Ethiopia and Malawi [5]. For instance, in the year 2012, about 260,000 new HIV infections occurred in children worldwide [6]. In Uganda, HIV prevalence has been rising since its lowest rate of 6.4 percent in 2006 [7]. Currently, 7.3 percent of Uganda's population is living with HIV [8]. New infections are diagnosed in 150,000 people each year, of whom 20,600 are children [7]. In addition, in 2012, 110,000 adolescents were living with HIV in Uganda [9]. The HIV prevalence in adolescents aged 15-17 years is $1.6 \%$ in females and 1.8 in males, while among adolescents aged 18-19 years, the prevalence is $5.1 \%$ in females and $1.5 \%$ in males [10]. In Uganda, data on whether these adolescents acquired HIV perinatally or behaviorally is not known. Understanding the sexual behaviors of PHIV can help us can help us explain some of the factors related the HIV infection rates in this population.

Current literature based on studies conducted in developed countries and focusing on sexual behaviours of adolescents and young people who acquired HIV behaviourally or perinatally highlights differences in risky sexual behaviours [11-14]. This data suggests that irrespective of how HIV was acquired, adolescents have high-risk behaviour characterised by having unprotected sex and multiple sexual partners [15]. There are various factors which have been found to be responsible for increasing the risk of being sexually active among adolescents. Contextual factors such as the use of alcohol or marijuana, living environment, caregivers' mental health increase the chances of engaging in penetrative sex among the youth [16]. In addition, living with only one or with neither parent or having low parental supervision increased the frequency of protected and unprotected sex [17]. Furthermore, not receiving instructions at school about pregnancy prevention increased the frequency of protected and unprotected sex [17].

Many PHIV adolescents are actively engaged in sexual activity and report prior or current sexual experience $[14,18]$. A study conducted in Uganda showed that $11.4 \%$ of females and $12.9 \%$ of males had their sexual debut between the ages of 15-19 years [19]. To reduce the risk of HIV transmission or acquisition of other HIV strains (super infection), the main focus of existing HIV programs is to encourage young clients with HIV infection to refrain from or postpone sexual activity $[18,20]$. Yet from sexual and reproductive health (SRH) and rights, adolescents need to be given adequate information so as to make appropriate decisions concerning their sexual and reproductive health.

The data available on sexual behaviour of HIV positive adolescents in Uganda has several shortfalls. It is mainly from qualitative studies and with few quantitative studies. Secondly, most of the data was collected from the central region in Uganda. This necessitates studies in other regions of the country to compare findings and as well as studies that use both qualitative and quantitative methods. In addition, the available data is not stratified among younger (10-14 years old) and older (15-19 years old). Moreover, the data does not segregate information from adolescents perinatally infected with HIV and those who acquired HIV through other means. Lastly, correlates and contextual factors of being sexually active in HIV perinatally-infected adolescents are not well documented.

In Uganda, the proportion and correlates of being sexually active among PHIV adolescent is not known. This curtails effective planning of potential health services for this population. The purpose of the current study was to describe the correlates of being sexual active among perinatally HIV-infected adolescents. This was a part of larger study that looked at sexual experiences, quality of care of SRH services and health related quality of life among PHIV adolescents.

\section{Methods}

\section{Study design and setting}

This was a cross sectional study of PHIV adolescents aged 10-19 years receiving care and treatment in 12 antiretroviral therapy (ART) clinics in three regions of Uganda (Eastern, Western and Northern). Data was collected from September 1, 2013 to March 30, 2014.

\section{Participant's selection}

Three regions (Northern, Eastern and Western) were purposefully-selected. The central region was excluded because previous studies on PHIV adolescents were conducted in this region. In each region, four health facilities were selected. The regional referral hospitals were purposefully-selected from each region because they receive referrals from the lower level facilities. To select the remaining facilities, a sampling frame comprising of all health facilities in each region with 50 or more clients aged $<15$ years were considered [21]. Three health facilities were then randomly selected from each of the regions.

The inclusion criteria for participants were being adolescents aged 10-19 years and knew their HIV serostatus. At each facility the participants who met the inclusion criteria and consented to participate in the study were selected through a consecutive sampling procedure. At each site, a research assistant recruited all the participants who were available in the ART clinic, and enrolled those who fulfilled the inclusion criteria and gave informed consent for participation, until the sample size was obtained. To verify and confirm PHIV status of the participants, medical records were checked to 
ascertain the HIV positive result, a positive test from parents, and absence of information that HIV was acquired sexually or through injections. The age at which the adolescents started attending the ART clinic was also reviewed and recorded to corroborate the PHIV status and possible source of infection. The research assistants were trained on interview skills and on how to ensure privacy and confidentiality. Trained research assistants conducted the interviewed the the participants in absence of their parents or guardians.

\section{Sample size determination}

The sample size was powered to determine the prevalence of being sexually active. The sample size was calculated using a prevalence of $33 \%$ of ever having sex, $95 \%$ confidence interval and an error margin of $5 \%$. The prevalence of $33 \%$ was used based on a previous study by Birungi et al. [22]. A design effect of 2 was used and we recruited 624 .

\section{Variable measurements}

Data were collected through face to face interviewer- administered questionnaires in a private room. The data collected from participants included socio-demographic characteristics (age at last birthday, gender, education level, religion marital status, living situation and occupation), sexual behaviour and practices ("having ever had sex", boyfriend/girlfriend, and intimate relationships), condom use (use of condom in the last 6 months and correct and consistent condom use every time the adolescent had sex), number of concurrent sexual partners, STI's, disclosure of HIV sero-status to the partner; pregnancy and procreation intentions; and peer influence. The primary outcome measured was having ever had sex, which was defined as heterosexual penetrative intercourse. Data on sexual experiences among adolescents was obtained using a series of validated questionnaires adopted from a number of tools $[19,23]$. The tools were piloted to remove ambiguity by reframing and rephrasing some questions.

\section{Data management and analysis}

Participant's age was grouped into 10-14 years and 15-19 years. Education status was grouped into in school and out of school, and education level was grouped into three categories: no education, primary and secondary. Occupation was grouped into three categories: students, unemployed and employed.

The proportion of those who had ever had sex was computed. To assess correlates of having ever had sex as the dependent variable and other variables, Pearson's chi square and Student $t$ test were used to measure the association between these variables and for categorical and continuous explanatory variables respectively.
Stepwise logistic regression models were built to identify independent predictors of ever had sex. During model development, all predictor variables with a $p$-value of $\leq 0.2$ [24] at bivariate analysis were considered for inclusion in the multivariate logistic regression model. Collinearity was assessed using a correlation matrix and cross-checked by the use of variance inflation factor which was set at 10 [25]. In case two variables were associated $(P<0.05)$, the variable explaining the largest variability (smaller $\mathrm{p}$ value at univariate analysis) was retained. Significance was set at 0.05 and all of the analyses were two tailed. Analyses were done using $\operatorname{STATA}^{\circ} 12$.

\section{Ethical review and approval}

Ethical reviews and approval were obtained from the Higher Degrees and Research Ethics Committee of the College of Health Sciences at Makerere University and the Uganda National Council for Science and Technology. Administrative clearance and permissions were also obtained from the management of each of the health facilities. Written informed consent was obtained from adolescents above 18 years. For adolescents below 18 years assent from the adolescents and consent from parents or guardians was obtained. All the participants who were in need of services such as family planning or screening for Sexually Transmitted Infections (STI's) were offered these services by referral. Participation was voluntary and all the interviews were conducted in private settings to ensure participant's confidentiality.

\section{Results}

A total of 624 perinatally HIV-infected adolescents participated in the study and their characteristics are presented in Table 1. Of these, 370/624 (59\%) were female, $458 / 624$ (73.4 \%) were in school at the time of the study and 356/624 had primary level education (57.6 \%). The mean age of the participants was 16.2 years (SD 2.1) and mean age of sexual debut was 15.8 years. The mean age at which the PHIV adolescents started attending the ART clinic was 6.2 years (SD 2.0).

Table 2 shows the sexual behaviours and other behaviours of the participants.. Of the 624, 519/624 (83\%) were currently on ARV's, 396/624 (64\%) had ever been in an intimate relationship, 206/624 (33\%) were currently in an intimate relationship and. 213 (34.\%) had ever had sexual intercourse. Of the latter, 144/213 (57\%) were female, 136/213 (64\%) had sex in the last six months, 93/213 (44\%) did not use condoms during the last sexual encounter, 165/213 (76\%) did not use condoms consistently, and 105/213 (49 \%) had been pregnant or made someone pregnant. In regard to STI's 101/624 (16 \%) reported having related symptoms. Of these, 65/101 (64 \%) had advised their partners to seek care. 
Table 1 Socio demographic characteristics of 624 perinatally HIV -infected adolescent in Uganda

\begin{tabular}{|c|c|c|c|}
\hline Characteristics & & $\begin{array}{l}\text { Frequency } \\
\text { (n) }\end{array}$ & $\begin{array}{l}\text { Percent } \\
(\%)\end{array}$ \\
\hline \multirow[t]{2}{*}{ Gender } & Females & 370 & 59.3 \\
\hline & Males & 254 & 40.7 \\
\hline \multirow[t]{2}{*}{ Age groups } & $10-14$ years & 114 & 18.3 \\
\hline & $15-19$ years & 510 & 81.4 \\
\hline \multirow[t]{5}{*}{ Religion $^{a}$} & Catholic & 260 & 41.8 \\
\hline & Protestant & 252 & 40.4 \\
\hline & Muslim & 44 & 7.1 \\
\hline & Born again & 58 & 9.3 \\
\hline & Other & 7 & 1.1 \\
\hline \multirow[t]{2}{*}{ Education status } & Out of school & 166 & 26.6 \\
\hline & In school & 458 & 73.4 \\
\hline \multirow[t]{3}{*}{ Level of education ${ }^{a}$} & No formal education & 30 & 4.8 \\
\hline & Primary level & 356 & 57.1 \\
\hline & Secondary level & 231 & 37.1 \\
\hline \multirow{4}{*}{$\begin{array}{l}\text { Highest level of education } \\
\text { hoped to complete }\end{array}$} & Primary & 12 & 2.6 \\
\hline & Secondary & 40 & 8.7 \\
\hline & Tertiary & 378 & 82.4 \\
\hline & Did not know & 28 & 6.1 \\
\hline \multirow[t]{3}{*}{ Occupation $^{a}$} & Students & 462 & 74 \\
\hline & Employed & 49 & 7.9 \\
\hline & employed & 86 & 13.7 \\
\hline \multirow[t]{3}{*}{ Region } & Western & 231 & 37 \\
\hline & Eastern & 173 & 27.7 \\
\hline & Northern & 220 & 35.3 \\
\hline \multirow[t]{2}{*}{ Distance to clinic } & Within $5 \mathrm{~km}$ & 197 & 31.5 \\
\hline & More than $5 \mathrm{~km}$ & 427 & 68.6 \\
\hline \multirow{5}{*}{$\begin{array}{l}\text { Parenthood status } \\
\text { (living status) }^{\mathrm{a}}\end{array}$} & Both parents & 105 & 16.8 \\
\hline & One parent (one dead) & 196 & 31.4 \\
\hline & One parent (other alive) & 51 & 8.2 \\
\hline & $\begin{array}{l}\text { Guardian/siblings } \\
\text { (parents dead) }\end{array}$ & 245 & 39.3 \\
\hline & Staying alone & 19 & 3.0 \\
\hline
\end{tabular}

${ }^{\mathrm{a} S o m e}$ responses were missing/unknown

Of the 624 adolescents, 396/624 (63.5\%) adolescents had ever been in relationships, of whom 196/396 (50 \%) had not disclosed their sero status to their partner, and 173/396 (44 \%) were aware of the HIV status of their partner. For the latter, 86/173 (50 \%) had HIV positive partners. About lifestyle, $15.9 \%$ (99/624) had ever drunk alcohol and/ smoked.

Table 3 shows stratified analysis comparing young and old adolescent's sexual behaviour. PHIV adolescents aged $10-14$ years had ever had sex $(2.8 \%$ vs $97.2 \%$; $\mathrm{p}<0.001)$ compared to those aged 15-19 years. About $3 \%(6 / 213)$
Table 2 Sexual and other behaviours of perinatally HIV- infected adolescents with HIV in Uganda

\begin{tabular}{|c|c|c|c|}
\hline Variable & $\begin{array}{l}\text { Total } \\
(\mathrm{N})\end{array}$ & & $n(\%)$ \\
\hline Currently on ARVs & 624 & Yes & $519(83.2)$ \\
\hline Ever had Intimate relationship & 624 & Yes & $396(63.5)$ \\
\hline Currently in intimate relationship & 624 & Yes & $206(33.0)$ \\
\hline Ever had sex & 624 & Yes & $213(34.1)$ \\
\hline Had sex in the last 6 months? & 213 & Yes & $136(63.9)$ \\
\hline \multirow[t]{3}{*}{ bHow often has sex: } & \multirow[t]{3}{*}{136} & $\geq 3$ times a week & $17(12.5)$ \\
\hline & & Once week & $41(30.2)$ \\
\hline & & Once a month & $78(57.4)$ \\
\hline \multirow{2}{*}{$\begin{array}{l}\text { Number of sexual partners } \\
\text { (last six months) }\end{array}$} & \multirow[t]{2}{*}{213} & 1 & $179(84.0)$ \\
\hline & & $\begin{array}{l}\text { More than } 1 \\
\text { partner }\end{array}$ & $34(16.0)$ \\
\hline a Used a condom at last sex & 213 & No & $93(43.7)$ \\
\hline${ }^{a}$ Consistent condom use & 213 & No & $165(77.5)$ \\
\hline${ }^{\mathrm{C}}$ Ever been pregnant & 144 & Yes & $82(56.9)$ \\
\hline${ }^{\mathrm{C}}$ Ever made someone pregnant & 69 & Yes & $23(33.3)$ \\
\hline $\begin{array}{l}\text { Aware of HIV status of partner } \\
\text { and disclosed }\end{array}$ & 396 & No & $223(56.3)$ \\
\hline Partner HIV + & 173 & Yes & $86(49.7)$ \\
\hline Disclosed HIV status & 396 & No & $196(49.5 \%)$ \\
\hline 'Ever lived with boy/girlfriend? & 213 & Yes & 95 (44.6) \\
\hline${ }^{\mathrm{a} E v e r}$ been married? & 213 & Yes & $46(21.6)$ \\
\hline \multicolumn{4}{|l|}{ Sexually transmitted infections } \\
\hline Been treated for an STD/STI? & 624 & Yes & $101(16.2)$ \\
\hline \multirow{4}{*}{$\begin{array}{l}\text { Ever suffered from the following } \\
\text { symptoms }\end{array}$} & \multirow[t]{4}{*}{101} & Genital sores & $15(14.8)$ \\
\hline & & Genital itching & $28(27.7)$ \\
\hline & & Genital discharge & $11(10.9)$ \\
\hline & & $\begin{array}{l}\text { Lower abdominal } \\
\text { pain }\end{array}$ & $17(16.8)$ \\
\hline $\begin{array}{l}\text { Advised partner to seek } \\
\text { treatment }\end{array}$ & 101 & Yes & $65(61.9)$ \\
\hline Peer influence & $\mathrm{N}$ & & n (\%) \\
\hline Ever smoked cigarette? & 624 & Yes & $18(2.9)$ \\
\hline Ever drunk alcohol? & 624 & Yes & $81(12.0)$ \\
\hline Has any friend taking alcohol? & 624 & Yes & $92(14.7)$ \\
\hline $\begin{array}{l}\text { Ever been Influenced to } \\
\text { smoke/take alcohol }\end{array}$ & 624 & Yes & $110(17.6)$ \\
\hline Sexuality & $\mathrm{N}$ & & Mean (SD) \\
\hline $\begin{array}{l}\text { Age when had first } \\
\text { boy/girlfriend (years) }\end{array}$ & 396 & & $15.67(1.5)$ \\
\hline ªge when had first sex (years) & 213 & & $15.83(1.7)$ \\
\hline Age when got married (years) & 46 & & $17.30(1.1)$ \\
\hline
\end{tabular}

An intimate relationship is an interpersonal relationship that involves physical or emotional intimacy. Physical intimacy is characterized by romantic or passionate attachment or sexual activity

Boyfriend and girlfriend means a regular female/ male companion with whom a person has a romantic as well as sexual relationship

${ }^{a}$ These refer to those 213 had ever had sex

${ }^{\mathrm{b}}$ These refer to those 136 who had sex in the last six months

'These refer to the females or males who had ever been sexually active 
Table 3 Stratified analysis comparing young adolescents and older adolescent's sexual behaviour among perinatally HIV-infected adolescents

\begin{tabular}{|c|c|c|c|}
\hline Variables & $\begin{array}{l}10-14 \text { years } \\
N(\%)\end{array}$ & $\begin{array}{l}15-19 \text { years } \\
N(\%)\end{array}$ & Total \\
\hline \multicolumn{4}{|l|}{ Ever had sex } \\
\hline Yes & $6(2.8)$ & $207(97.2)$ & $213(100)$ \\
\hline No & $108(27.3)$ & $303(73.7)$ & $411(100)$ \\
\hline \multicolumn{4}{|l|}{ Age at first sex } \\
\hline $10-14$ & $6(21.4)$ & 22 (78.6) & $28(100)$ \\
\hline $15-19$ & - & $185(100)$ & $185(100)$ \\
\hline \multicolumn{4}{|c|}{ Condom use at last sex } \\
\hline Yes & $3(2.5)$ & $117(97.5)$ & $120(100)$ \\
\hline No & $3(3.3)$ & $90(96.7)$ & $93(100)$ \\
\hline \multicolumn{4}{|c|}{ Number of partners } \\
\hline One & $6(3.4)$ & 173 (96.6) & $179(100)$ \\
\hline >one partner & - & $34(100)$ & $34(100)$ \\
\hline
\end{tabular}

of adolescents aged 10-14 years and 22/213 (10 \%) of adolescent aged 15-19 years had their first sex before the age of 15. In regard to condom use at last sex, adolescents aged 10-14, 3/120 (2.5 \%) had used condoms compared to 117/ $120(97.5 \%)$ adolescents aged $15-19$ years. None of the adolescents aged 10-14 had more than one sexual partner. However, 34/213 (16\%) of the adolescents who had ever had sex had more than one concurrent sexual partner.

\section{Factors associated with ever having had sex}

The factors associated with ever having had sex among PHIV are presented in Tables 4 and 5. The results show that female gender $(\mathrm{OR}=1.71,95 \% \mathrm{CI}=1.21-2.42)$, age group of 15-19 years, $(\mathrm{OR}=12.38,95 \% \mathrm{C} \mathrm{I}=5.34-28.7)$, and living alone $(\mathrm{OR}=5.37,95 \% \mathrm{CI}$ 1.79-16.09), were significantly associated with ever having sexual intercourse. On the other hand being in school $(\mathrm{OR}=0.14$, $95 \% \mathrm{CI}=0.10-0.21)$, receipt of STI treatment $(\mathrm{OR}=$ $0.14,95 \%$ CI $0.09-0.23)$, not drinking alcohol (OR = 0.38, 95 \% CI (0.24 - 0.61), not smoking (OR = 0.10, $95 \%$ $\mathrm{CI}=0.03-0.34)$, and not having a friend who drinks or smokes decreased the risk of ever having had sex $\mathrm{OR}=$ $0.30,95 \%$ CI (0.19-0.47). And as shown in Table 6, the independent predictors of being in this sample were; age group of $15-19$ years $(\mathrm{AOR}=6.28,95 \% \mathrm{CI}=95 \% 2.63-$ 14.99), being in school, ( $\mathrm{AOR}=0.20,95 \% \mathrm{CI}=0.13-0.30)$, living alone, $(\mathrm{AOR}=4.3,95 \% \mathrm{CI}=1.13-16.62)$, not ever been treated for STI (AOR $0.1995 \%$ CI 0.11-0.32), and not ever drunk alcohol $(\mathrm{AOR}=0.49,95 \%$ CI 0.28-0.87).

\section{Discussion}

The aim of this of this paper was to investigate the the correlates of ever having had sex among PHIV adolescents. The findings of the study show that one in three
PHIV adolescents had ever had sex and the correlates of ever having had sex were age, school status, living alone without parents and alcohol use. . About 16 per cent engaged in risky sexual behaviours characterised by multiple, concurrent partners and are at risk of HIV reinfection, pregnancy and STIs.

Sexual experiences are a sensitive matter. Collecting data on sexual experiences is could lead socially desirable responses. We used several measures to address this: We assured adolescents of confidentiality by conducting the interview in a private room; permission was sought from the adolescents, they were informed about the importance of the study and were assured that everything discussed in the session would be kept confidential and would not be shared with the health providers or their parent. We asked sensitive questions in many different ways. All the questions were answered with no skips; data was collected by research assistants who are not part of the clinic staff.

Adolescents' risky sexual relationships put them at risk of HIV re-infection, pregnancy and STIs. About a third of PHIV adolescents who participated in the study reported that they had ever had sex, with some reporting having unprotected sex .If the adolescents don't know the sero status of their partners they can infect them with HIV and also be re-infected. If they are not adhering to ART, the females can get pregnant and pass on HIV infection to their new-borns. It is apparent that the PHIV adolescents interviewed either do not have knowledge about the dangers of having unprotected sex or if they do, have not appreciated the dangers involved and are not adhering to the safer sexual practices they have been taught. According to the SRH and rights framework, adolescents need to be given adequate information so as to make appropriate decisions concerning their sexual and reproductive health. Regardless of their HIV status, they have the freedom to choose partners and even have sexual relationships, but in compliance with the laws of the country. They also have the responsibility to avoid, prevent or mitigate adverse effects of their sexual behaviours including re-infection and resultant HIV drugs resistance. They thus need to have adequate information and support to make informed decisions about their sexuality and sexual and reproductive health. This includes information on safe sexual practices and behaviours and contraception. Generally these findings are consistent with those of other studies done in Uganda, and in developed and less developed countries which have indicated that PHIV adolescents begin to explore their sexuality by dating and getting involved in relationships by 10-14 years [26-30]. A higher proportion of PHIV adolescents in this study were sexually active ( $34 \%$ versus $12 \%$ of the adolescents who had sex intercourse before age 15 in the general population [10]. 
Table 4 Likelihood of ever having had sex by socio demographic factor for perinatally HIV-infected adolescents in Uganda $(2013 / 2014)$

\begin{tabular}{|c|c|c|c|c|c|}
\hline \multirow[t]{2}{*}{ Variables } & & \multicolumn{2}{|c|}{ Sexually active } & \multirow{2}{*}{$\begin{array}{l}\text { Unadjusted } \\
\text { OR (95\% Cl) }\end{array}$} & \multirow[t]{2}{*}{$P$-value* } \\
\hline & & Yes N (\%) & No N (\%) & & \\
\hline \multirow[t]{2}{*}{ Sex } & Male & 69 (32.39) & $185(45.01)$ & 1 & 0.001 \\
\hline & Female & $144(67.61)$ & 226 (54.99) & $1.71(1.21-2.42)$ & \\
\hline \multirow[t]{2}{*}{ Age groups } & $10-14$ years & $6(2.82)$ & $108(26.41)$ & 1 & 0.001 \\
\hline & $15-19$ years & 207 (97.18) & 301 (73.59) & $12.38(5.34-28.70)$ & \\
\hline \multirow[t]{4}{*}{ Religion } & Catholic & $88(41.90)$ & $172(41.85)$ & 1 & 0.83 \\
\hline & Protestant & $83(39.52)$ & $169(41.12)$ & $0.96(0.66-1.39)$ & 0.23 \\
\hline & Muslim & $19(9.05)$ & $25(6.08)$ & $1.49(0.78-2.84)$ & 0.51 \\
\hline & Born again & $17(8.10)$ & $41(9.98)$ & $0.81(0.44-1.51)$ & \\
\hline \multirow[t]{2}{*}{ Education status } & Out of school & $110(51.64)$ & $52(12.65)$ & 1 & 0.001 \\
\hline & In school & $103(47.89)$ & $356(86.62)$ & $0.14(0.10-0.21)$ & \\
\hline \multirow[t]{3}{*}{ Level of education } & None & $13(6.10)$ & $17(4.21)$ & 1 & 0.15 \\
\hline & Primary level & $109(51.17)$ & $247(61.14)$ & $0.58(0.27-1.23)$ & 0.68 \\
\hline & Secondary level & $91(42.72)$ & $140(34.65)$ & $0.85(0.39-1.83)$ & \\
\hline \multirow[t]{3}{*}{ Education level hoped to complete } & Primary & $30(17.96)$ & $35(9.07)$ & 1 & 0.13 \\
\hline & Secondary & $38(22.75)$ & $72(18.65)$ & $0.62(0.33-1.15)$ & 0.001 \\
\hline & Tertiary & $99(59.28)$ & $279(72.28)$ & $0.41(0.24-0.71)$ & \\
\hline \multirow[t]{3}{*}{ Occupation } & Students & $102(52.04)$ & $360(89.78)$ & 1 & 0.001 \\
\hline & Volunteers(employed) & $33(16.84)$ & $16(3.99)$ & $7.28(3.85-13.75)$ & 0.001 \\
\hline & Stay home & $61(31.12)$ & $25(6.23)$ & $8.61(5.15-14.41)$ & \\
\hline \multirow[t]{3}{*}{ Region } & Western & $65(30.52)$ & $166(40.39)$ & 1 & 0.001 \\
\hline & Eastern & $72(33.80)$ & $101(24.57)$ & $1.82(1.20-2.76)$ & 0.14 \\
\hline & Northern & $76(35.68)$ & $144(35.04)$ & $1.35(0.90-2.01)$ & \\
\hline \multirow[t]{4}{*}{ Living situation } & Both parents & $36(17.39)$ & $69(16.87)$ & 1 & 0.52 \\
\hline & One parent (one dead) & $60(28.99)$ & $136(33.25)$ & $0.85(0.51-1.40)$ & 0.72 \\
\hline & One parent (other alive) & 19 (9.18) & $32(7.82)$ & $1.14(0.57-2.28)$ & 0.65 \\
\hline & & 78 (37.68) & $167(40.83)$ & $0.90(0.55-1.45)$ & \\
\hline
\end{tabular}

*Fisher's exact test was used where we had a cell count less than 5

The pregnancy intentions of HIV-positive clients are driven not only by an HIV diagnosis but by individual concerns as well as larger societal and cultural expectations [31]. In the current study PHIV adolescents who reported having ever had sex, $49 \%$ had ever been pregnant or impregnated. A number of the PHIV adolescents reporting pregnancy had been in care for a long time as shown by the mean age at which they joined care. Whereas it is assumed that since these adolescents have been in care for a long time they are exposed to many sexual and reproductive messages this may not be the case. Access to SRH messages depends on the quality of SRH services in ART clinics or may depend on whether the adolescents are from urban or rural area [32]. Therefore by being sexually active, PHIV adolescents are at risk of early pregnancy, contracting STIs and reinfection; and others at risk of contracting HIV/STIs.
The findings implies that the current strategies and health programs used for health education and to stop transmission of HIV specifically those targeting PHIV adolescents need to be re-visited because a large number are sexually active or are not having protected sex.

The findings of the current study also show that correct and consistent condom use was low (22\%) compared to the general population which stands at $25.5 \%$ and $31.7 \%$ for females and males respectively [8]. Findings of prior studies revealed that for HIV positive adolescents who were sexually active, many were not consistently using condoms $[15,33]$. Another study observed that PHIV adolescents are less likely to consistently use condoms compared to those who are HIV negative [34]. The fact that most adolescents who were in relationships did not know their partners' sero status or disclose their sero status to their partners implies 
Table 5 Likelihood of medical and life style factors associated with ever having had sex among perinatally HIV -infected adolescents

\begin{tabular}{|c|c|c|c|c|c|}
\hline \multirow[t]{2}{*}{ Variables } & & \multicolumn{2}{|c|}{ Sexually active } & \multirow{2}{*}{$\begin{array}{l}\text { Unadjusted } \\
\text { OR (95\% Cl) }\end{array}$} & \multirow[t]{2}{*}{$P$-value } \\
\hline & & Yes N (\%) & No N (\%) & & \\
\hline \multirow[t]{2}{*}{ Ever been treated for an STD/STI } & Yes & $73(34.43)$ & $28(6.86)$ & 1 & \multirow[t]{2}{*}{0.001} \\
\hline & No & $139(65.57)$ & $380(93.14)$ & $7.1(4.42-11.48)$ & \\
\hline \multirow[t]{2}{*}{ Ever smoked cigarette } & Yes & $15(7.08)$ & $3(0.78)$ & 1 & \multirow[t]{2}{*}{0.001} \\
\hline & No & $197(92.92)$ & $408(99.27)$ & $0.10(0.03-0.34)$ & \\
\hline \multirow[t]{2}{*}{ Ever drunk alcohol } & Yes & $44(20.66)$ & $37(9.00)$ & 1 & \multirow[t]{2}{*}{0.001} \\
\hline & No & $169(79.34)$ & $374(91.00)$ & $0.38(0.24-0.61)$ & \\
\hline \multirow[t]{2}{*}{ Has a friend who is smoking cigarette } & Yes & $54(25.47)$ & $38(9.29)$ & 1 & \multirow[t]{2}{*}{0.001} \\
\hline & No & $158(74.53)$ & $371(90.71)$ & $0.30(0.19-0.47)$ & \\
\hline \multirow[t]{2}{*}{ Has a friend who is drinking alcohol } & Yes & $100(47.17)$ & 85 (20.68) & 1 & \multirow[t]{2}{*}{0.001} \\
\hline & No & $112(52.83)$ & $326(79.32)$ & $0.29(0.20-0.42)$ & \\
\hline \multirow[t]{2}{*}{ Ever been influenced to smoke/drink } & Yes & $67(31.90)$ & $43(10.49)$ & 1 & \multirow[t]{2}{*}{0.001} \\
\hline & No & $143(68.10)$ & 367 (89.51) & $0.25(0.16-0.38)$ & \\
\hline
\end{tabular}

*Fisher's exact test was used where we had a cell count less than 5

increased risk of HIV transmission or re-infection in/by sexually active PHIV adolescents. Studies have also found that PHIV adolescents engage in risky sexual behaviours even when they know their status [27, 35-37].

Our study suggests that one of the determinants of sexual activity among PHIV adolescents is peer influence. Peer influence informs the normative or acceptable behaviour for certain ages of adolescents [2, 38]. Peer influence leads to adoption a particular type of behaviour, dress, or attitude in order to be accepted as part of a group of their equals ("peers"). Adolescents' sexual behaviours are influenced by the sexual attitudes and behaviours of their friends $[39,40]$. This is consistent with other studies that have shown that youths who had friends who were sexually experienced have greater odds of early sexual debut $[2,39,41]$. In our study PHIV

Table 6 Adjusted effects for predictors of ever having had sex from a multiple logistic regression among perinatally HIV -infected adolescents

\begin{tabular}{|c|c|c|c|c|}
\hline \multirow[b]{2}{*}{ Variables } & \multicolumn{2}{|l|}{ Sexually active } & \multirow[b]{2}{*}{ Adjusted OR (95\% Cl) } & \multirow[b]{2}{*}{ P-Value } \\
\hline & Yes num. (\%) & No num. (\%) & & \\
\hline \multicolumn{5}{|l|}{ Age groups } \\
\hline $10-14$ years & $6(2.82)$ & $108(26.41)$ & 1 & 0.001 \\
\hline 15 - 19 years & 207 (97.18) & $301(73.59)$ & $6.28(2.63-14.99)$ & \\
\hline Education status & & & & 0.001 \\
\hline Out of school & $111(52.11)$ & $55(13.38)$ & 1 & \\
\hline In school & $102(47.89)$ & $356(86.62)$ & $0.20(0.13-0.30)$ & \\
\hline \multicolumn{5}{|c|}{ Parenthood status - Living with } \\
\hline Both parents & $36(17.39)$ & $69(16.87)$ & 1 & 0.68 \\
\hline One parent (one dead) & $60(28.99)$ & $136(33.25)$ & $0.88(0.48-1.61)$ & 0.78 \\
\hline One parent (other alive) & $19(9.18)$ & $32(7.82)$ & $1.13(0.47-2.69)$ & 0.61 \\
\hline Guardian/siblings & $78(37.68)$ & $167(40.83)$ & $0.86(0.48-1.54)$ & 0.03 \\
\hline Living alone & $14(6.76)$ & $5(1.22)$ & $4.33(1.13-16.62)$ & \\
\hline \multicolumn{5}{|c|}{ Ever been treated for an STD/STI } \\
\hline Yes & $73(34.43)$ & $28(6.86)$ & 1 & 0.001 \\
\hline No & $139(65.57)$ & $380(93.14)$ & $0.19(0.11-0.32)$ & \\
\hline \multicolumn{5}{|l|}{ Ever drunk alcohol } \\
\hline Yes & $44(20.66)$ & $37(9.00)$ & 1 & 0.02 \\
\hline No & $169(79.34)$ & $374(91.00)$ & $0.49(0.28-0.87)$ & \\
\hline
\end{tabular}

$A O R$ adjusted odds ratio, adjusted for variables included in the model 
adolescents who consumed alcohol and smoked cigarettes were more likely to have ever had sex. Other studies have also reported similar findings and these show that adolescents' use of alcohol and other drugs has been associated with sexual risk [42-44]. Alcohol compromises the decision-making or leads to disinhibition when adolescents are drunk, and this adds another dimension to the increased behavioral risks of PHIV adolescents [45].

Schools can be a primary source of information about prevention methods in the fight against HIV [46]. This study has shown that being in school was associated with lower odds ofever having had sex. Education also accelerates behaviour change among young men and women by making them more receptive to prevention messages [47]. Schools also provide adults and young people with the life skills they need to make informed choices and to develop both economic and intellectual independence [47]. Studies have shown that increasing number of years are associated with a less likelihood of having a casual sexual partner and a high likelihood of condom use [48]. It has also been already reported in other countries that better-education for girls tended to delay having sex and increased instance on condoms use in their partners [22, 49].

Living arrangements of PHIV adolescent and availability of parental guidance is another key factor that determines the adolescent is sexually active or not among PHIV adolescents. In our study living alone was independently associated with ever having had sex. This was not surprising because adolescents living alone have no guidance from elders, parents or siblings [50]. Therefore they luck in social support and social skills and it is very easy for them to become more vulnerable to peer influence and subsequent risky sexual behaviours. Studies have shown that living alone or living with siblings is associated with risky sexual behaviours compared to living with older people such as grandparents, parents or guardians $[15,16,51,52]$.

\section{Limitations of the study}

The study had several limitations emerging from the self-report method of data collection such as the recall bias (recall of sexual activity) and the potential for under-reporting of sexual behaviour due to the sensitive nature of the subject. Participants may have forgotten or may have been embarrassed to reveal information their sexual activity especially for the females.The males may have exaggerated their sexuality activities (20). In addition, it is possible that the participants may have forgotten important information on issues like condom use and number of partners. On participant selection, information was not available on the mother's HIV status; this could have introduced some misclassification bias. We however collected information on age at which adolescents started visiting ART clinic and we used this as a proxy of perinatal infection. Furthermore, data on HAART was not collected and this might have added valuable relevancy since treatment improves health and quality of life, and likelihood of forming relationships and being sexually active. Testing for STIs and monitoring of HIV parameters such as CD4 count and viral load were not part of the study. These measurements are critically linked to sexual behaviour in people who are on ART $[53,54]$.

\section{Conclusion and implication}

Perinatally HIV-infected (PHIV) adolescents in Uganda are sexually active and engage in risky sexual behaviours such as having unprotected sex intercourse. The majority of the PHIV adolescents do not know the sero-status of their partners and do not use condoms consistently. The level of ever having had sex and risky sexual behaviours increases the risk of HIV transmission and HIV re-infections among the sexual partners of PHIV adolescents. The key correlates of ever having had sex among PHIV adolescents are age, school status, and parenthood status and alcohol consumption. There is need for concerted efforts and interventions to ensure that PHIV adolescents stay in school have a stable family support and receive effective sexual and reproductive health educations that reduces risky sexual behaviours and substance abuse.

\section{Competing interests \\ The authors declare that they have no competing interests}

\section{Authors' contributions}

SNM designed the study, collected and analysed the data, drafted the paper; NK contributed to the design the study and reviewed the paper. RW contributed to the analysis, drafting and reviewing the paper; LEE contributed to the design the study and reviewed the paper and DKK contributed to the design the study, analysed the data and reviewed the paper. All the authors approved the final draft of the paper.

\section{Acknowledgement}

The authors extend their gratitude and appreciation to all the participants who participated in the study, the staff of health facilities where the study was carried out and Doctoral committee members DR Sabrina Kitaka, Prof Josephat Byamugisha and Dr Rose Chalo Nabirye and field coordinator Gloria Ninsiima.

The work was supported by Grant Number 5R24TW008886 supported by OGAC, NIH and HRSA. Its contents are solely the responsibility of the authors and do not necessarily represent the official views of the supporting offices. This research was partially funded by a Fellowship award provided by the Consortium for Advanced Research Training in Africa CARTA has been funded by the Wellcome Trust (UK) Grant No: 087547/Z/08/Z, the Department for International Development (DfID) under the Development Partnerships in Higher Education (DelPHE), the Carnegie Corporation of New York Grant No: B 8606, the Ford Foundation Grant No: 1100-0399, and the Bill and Melinda Gates Foundation Grant No: 51228.

\section{Author details}

'Department of Nursing, Makerere University, Kampala, Uganda. ${ }^{2}$ School of Public Health, Makerere University, Kampala, Uganda. ${ }^{3}$ Department of Neurobiology, Care Sciences and Society, Karolinska Institutet, Stockholm, Sweden. ${ }^{4}$ Department of Infectious Diseases, Karolinska University Hospital, 
Stockholm, Sweden. ${ }^{5}$ School of Health Sciences, City University London, London, UK. ${ }^{6}$ Department of Obstetrics and Gynaecology, Makerere University, Kampala, Uganda.

\section{Received: 10 March 2015 Accepted: 5 October 2015}

Published online: 16 October 2015

\section{References}

1. Sohn AH, Hazra R. The changing epidemiology of the global paediatric HIV epidemic: keeping track of perinatally HIV-infected adolescents. J Int AIDS Soc. 2013;16(18555):18555.

2. World Health Organisation. Strengthening the health sector response to adolescent health and development. (CAH) DoCaAHaD, editor. 20 Avenue Appia, 1211 Geneva 27, Switzerland 2009.

3. Redd AD, Ssemwanga D, Vandepitte J, Wendel SK, Ndembi N, Bukenya J, et al. Rates of HIV-1 superinfection and primary HIV-1 infection are similar in female sex workers in Uganda. AIDS, England. 2014;28(14):2147-52.

4. Joint United Nations Programme on HIV/AIDS. Global report: UNAIDS report on the global AIDS epidemic. 2013.

5. Joint United Nations Programme on HIV/AIDS. Report on the Global AIDS Epidemic. 2013.

6. Joint United Nations Programme on HIV/AIDS. Global Fact Sheet. 2013.

7. Joint United Nations Programme on HIV AIDS. Global Report 2012: AIDSinfo. Geneva, Switzerland, UNAIDS. 2012;10

8. Ministry of Health. Uganda AIDS Indicator Survey. 2011.

9. United Nations Children's Fund. Children and AIDS sixth Stocktaking report. 2013

10. Uganda Ministry of Health and ICF International. 2011 Uganda AIDS Indicator Survey: Key Findings. Calverton, Maryland, USA: MOH and ICF International. 2012.

11. Tassiopoulos K, Moscicki AB, Mellins C, Kacanek D, Malee K, Allison S, et al. Sexual risk behavior among youth with perinatal HIV infection in the United States: predictors and implications for intervention development. Clin Infect Dis. 2013;56(2):283-90. doi:10.1093/cid/cis816.

12. Wiener LS, Battles HB, Wood LV. A longitudinal study of adolescents with perinatally or transfusion acquired HIV infection: sexual knowledge, risk reduction self-efficacy and sexual behavior. AIDS and behavior. 2007;11(3):471-8. doi:10.1007/s10461-006-9162-y.

13. Setse RW, Siberry GK, Gravitt PE, Moss WJ, Agwu AL, Wheeling JT, et al. Correlates of sexual activity and sexually transmitted infections among human immunodeficiency virus-infected youth in the LEGACY cohort, United States, 2006. Pediatr Infect Dis J. 2011;30(11):967-73. doi:10.1097/INF.0b013e3182326779.

14. Tanney MR, Naar-King S, Murphy DA, Parsons JT, Janisse H. Multiple risk behaviors among youth living with human immunodeficiency virus in five U.S. cities. J Adolesc Health. 2010;46(1):11-6. doi:10.1016/ j.jadohealth.2009.05.017.

15. Koenig L, Pals SL, Chandwani S, Hodge K, Abramowitz S, Barnes W, et al. Sexual transmission risk behavior of adolescents With HIV acquired perinatally or through risky behaviors. J Acquir Immune Defic Syndr. 2010;55((3):380-90. doi:10.1097/QAl.0b013e3181f0ccb6.

16. Elkington KS, Bauermeister JA, Robbins RN, Gromadzka O, Abrams EJ, Wiznia A, et al. Individual and contextual factors of sexual risk behavior in youth perinatally infected with HIV. AIDS patient care and STDs. 2012;26(7):411-22. doi:10.1089/apc.2012.0005

17. Oliveira-Campos M, Giatti L, Malta D, Barreto SM. Contextual factors associated with sexual behavior among Brazilian adolescents. Ann Epidemiol. 2013;23(10):629-35.

18. Baryamutuma R, Baingana F. Sexual, reproductive health needs and rights of young people with perinatally acquired HIV in Uganda. Afr Health Sci. 2011;11(2):211-8.

19. Ministry of Health. Uganda AIDS Indicator Survey (AIS). Calverton, Maryland, USA Ministry of Health and ICF International; 2012

20. Obare F, Birungi $H$. The limited effect of knowing they are HIV-positive on the sexual and reproductive experiences and intentions of infected adolescents in Uganda. Population studies. 2010;64(1):97-104. doi:10.1080/ 00324720903427575

21. Ministry of Health. Number of clients on ART by regimen as of December 2011. 2011.

22. Birungi $H$, Mugisha JF, Obare F, Nyombi JK. Sexual behavior and desires among adolescents perinatally infected with human immunodeficiency virus in Uganda: implications for programming. J Adolesc Health. 2009;44(2):184-7. doi:10.1016/j.jadohealth.2008.06.004
23. Ministry of Health. Assessment of adolescent HIV care and treatment services in Uganda 2014

24. Hosmer DW, Lemeshow S. Applied Logistic Regression Analysis. New York: John Wiley and Sons Inc.; 2000.

25. Kutner MH, Nachtsheim CJ, Neter J. Applied Linear Regression Models. Fourth ed. McGraw-Hill Irwin: 2004)

26. Bakeera-Kitaka S, Nabukeera-Barungi N, Nostlinger C, Addy K, Colebunders R. Sexual risk reduction needs of adolescents living with HIV in a clinical care setting. AIDS Care. 2008;20(4):426-33. doi:10.1080/09540120701867099.

27. Birungi $H$, Obare F, Mugisha JF, Evelia H, Nyombi J. Preventive service needs of young people perinatally infected with HIV in Uganda. AIDS Care. 2009;21(6):725-31. doi:10.1080/09540120802511901.

28. Bauermeister JA, Elkington KS, Robbins RN, Kang E, Mellins CA. A prospective study of the onset of sexual behavior and sexual risk in youth perinatally infected with HIV. J Sex Res. 2012;49(5):413-22. doi:10.1080/ 00224499.2011.598248

29. Ezeanolue EE, Wodi AP, Patel R, Dieudonne A, Oleske JM. Sexual behaviors and procreational intentions of adolescents and young adults with perinatally acquired human immunodeficiency virus infection: experience of an urban tertiary center. J Adolesc Health. 2006;38(6):719-25. doi:10.1016/ j.jadohealth.2005.06.015.

30. Fernet M, Wong K, Richard ME, Otis J, Levy JJ, Lapointe N, et al. Romantic relationships and sexual activities of the first generation of youth living with HIV since birth. AIDS Care. 2011;23(4):393-400. doi:10.1080/ 09540121.2010 .516332

31. Gruskin S, Firestone R, Maccarthy S, Ferguson L. HIV and pregnancy intentions: do services adequately respond to women's needs? Am J Public Health. 2008:98(10):1746-50.

32. Folayan MO, Odetoyinbo M, Brown B, Harrison A. Differences in sexual behaviour and sexual practices of adolescents in Nigeria based on sex and self-reported HIV status. Reprod Health. 2014;11(83):1742-4755.

33. Mmari KN, Kaggwa E, Wagman J, Gray R, Wawer M, Nalugoda F. Risk and protective correlates of young women's first sexual experiences in Rakai Uganda. Int Perspect Sex Reprod Health. 2013;39(3):153-62.

34. Beyeza-Kashesya J, Kaharuza F, Ekstrom AM, Neema S, Kulane A, Mirembe F. To use or not to use a condom: a prospective cohort study comparing contraceptive practices among HIV-infected and HIV-negative youth in Uganda. BMC infectious diseases. 2011;11:144. doi:10.1186/1471-2334-11-144.

35. Mhalu A, Leyna GH, Mmbaga EJ. Risky behaviours among young people living with HIV attending care and treatment clinics in Dar Es Salaam, Tanzania: implications for prevention with a positive approach. J Int AIDS Soc. 2013;16(17342):17342

36. Andriamahenina R, Ravelojaona B, Rarivoharilala E, Ravaoarimalala C, Andriamiadana J, Andriamahefazafy B, et al. AIDS in Madagascar. I. Epidemiology, projections, socioeconomic impact, interventions. Bull Soc Pathol Exot. 1998;91(1):68-70

37. Fair C, Albright J. "Don't tell him you have HIV unless he's 'the one'": romantic relationships among adolescents and young adults with perinatal HIV infection. AIDS Patient Care and STDs. 2012;26(12):746-54. doi:10.1089/ apc.2012.0290

38. Sallis J, Owen N. Ecological models of health behavior Health Behavior and Health Education: Theory, Research and Practice, vol 3rd ed. San Francisco: Calif: Jossey-Bass; 2002.

39. Sieving RE, Eisenberg ME, Pettingell S, Skay C. Friends' influence on adolescents' first sexual intercourse. Perspect Sex Reprod Health. 2006:38(1):13-9.

40. Potard C, Courtois R, Rusch E. The influence of peers on risky sexual behaviour during adolescence. Eur J Contracept Reprod Health Care. 2008:13(3):264-70

41. Miranda-Diaz M, Corcoran K. "All my friends are doing it:" the impact of the perception of peer sexuality on adolescents' intent to have sex. J Evid Based Soc Work. 2012;9(3):260-4. doi:10.1080/15433714.2012.672923.

42. Santelli JS, Robin L, Brener ND, Lowry R. Timing of alcohol and other drug use and sexual risk behaviors among unmarried adolescents and young adults. Fam Plann Perspect. 2001;33(5):200-5

43. Elkington KS, Bauermeister JA, Brackis-Cott E, Dolezal C, Mellins CA. Substance use and sexual risk behaviors in perinatally human immunodeficiency virusexposed youth: roles of caregivers, peers and HIV status. J Adolesc Health. 2009:45(2):133-41. doi:10.1016/j.jadohealth.2009.01.004

44. Tilahun M, Ayele $\mathrm{G}$. Factors associated with age at first sexual initiation among youths in Gamo Gofa, south west Ethiopia: a cross sectional study. BMC Public Health. 2013;13(622):1471-2458. 
45. Sloan FA, Eldred LM, Davis DV. Addiction, drinking behavior, and driving under the influence. Subst Use Misuse. 2014;49(6):661-76.

46. Al-Iryani B, Basaleem H, Al-Sakkaf K, Crutzen R, Kok G, van den Borne B. Evaluation of a school-based HIV prevention intervention among Yemeni adolescents. BMC Public Health. 2011;11(279):1471-2458.

47. Basen-Engquist KCK, Parcel GS, Kirby D, Banspach SW, Carvajal SC, et al. Schoolwide effects of a multicomponent HIV, STD, and pregnancy prevention program for high school students. Health Educ Behav. 2001;28(2):166-85

48. Coyle K, Basen-Engquist K, Kirby D, Parcel G, Banspach S, Collins J, et al. Safer choices: reducing teen pregnancy, HIV, and STDs. Public Health Rep. 2001;1:82-93.

49. Markham CM, Shegog R, Leonard AD, Bui TC, Paul ME. +CLICK: harnessing web-based training to reduce secondary transmission among HIV-positive youth. AIDS Care. 2009;21(5):622-31.

50. Campbell T, Beer H, Wilkins R, Sherlock E, Merrett A, Griffiths J. "I look forward. I feel insecure but I am ok with it". The experience of young HIV+ people attending transition preparation events: a qualitative investigation. AIDS Care. 2010;22(2):263-9. doi:10.1080/09540120903111460.

51. Rwenge M. Sexual risk behaviors among young people in bamenda. Cameroon. 2000;26(3):18-23.

52. Twa-Twa JM. The role of the environment in the sexual activity of schoo students in Tororo and Pallisa Districts of Uganda. Health Transit Rev. 1997;7:67-81.

53. Remien RH, Exner TM, Morin SF, Ehrhardt AA, Johnson MO, Correale J, et al. Medication adherence and sexual risk behavior among HIV-infected adults: implications for transmission of resistant virus. AIDS and behavior. 2007:11(5):663-75

54. Wilson TE, Barron Y, Cohen M, Richardson J, Greenblatt R, Sacks HS, et al. Adherence to antiretroviral therapy and its association with sexual behavio in a national sample of women with human immunodeficiency virus. Clin Infect Dis. 2002;34(4):529-34.

\section{Submit your next manuscript to BioMed Central and take full advantage of:}

- Convenient online submission

- Thorough peer review

- No space constraints or color figure charges

- Immediate publication on acceptance

- Inclusion in PubMed, CAS, Scopus and Google Scholar

- Research which is freely available for redistribution 